\title{
William C. Smith (sous la direction de), The Global Testing Culture. Shaping Education Policy, Perceptions and Practice
}

Oxford, Symposium Books, 2016

Xavier Pons

\section{Q OpenEdition}

Édition électronique

URL : https://journals.openedition.org/ries/5471

DOI : 10.4000/ries.5471

ISSN : 2261-4265

Éditeur

France Education international

\section{Édition imprimée}

Date de publication : 1 septembre 2016

Pagination : 35-36

ISBN : 978-2-85420-611-1

ISSN : $1254-4590$

\section{Référence électronique}

Xavier Pons, «William C. Smith (sous la direction de), The Global Testing Culture. Shaping Education Policy, Perceptions and Practice », Revue internationale d'éducation de Sèvres [En ligne], 72 I septembre 2016, mis en ligne le 01 septembre 2016, consulté le 01 juillet 2021. URL : http:// journals.openedition.org/ries/5471; DOI : https://doi.org/10.4000/ries.5471

Ce document a été généré automatiquement le 1 juillet 2021.

(c) Tous droits réservés 


\section{William C. Smith (sous la direction de), The Global Testing Culture. Shaping Education Policy, Perceptions and Practice}

Oxford, Symposium Books, 2016

\section{Xavier Pons}

La thèse de cet ouvrage est synthétisée dans son titre et dans l'introduction que nous livre William Smith. Ce dernier soutient que le développement sans précédent de tests standardisés dans le monde débouche sur la construction progressive d'une culture globale du testing qui repose sur trois piliers organisés en cercles concentriques : des présupposés fondamentaux (core assumptions) comme le positivisme et l'individualisme ; des valeurs de référence (le droit à l'éducation, la décentralisation, le néolibéralisme, etc.) et des modèles culturels qui traduisent en rôles et comportements attendus ces valeurs et présupposés (comme le modèle des parents consommateurs d'un marché scolaire néolibéral). Il mobilise pour cela les travaux de la "World Culture Theory ", qui identifient les similarités de pratiques et de politiques éducatives dans des contextes différents pour théoriser sur leur base l'existence de modèles culturels mondiaux.

2 L'ouvrage est ainsi structuré en trois parties au sein desquelles 25 auteurs aux profils internationaux variés illustrent diverses dimensions du déploiement et de l'influence de cette culture globale.

3 La première partie analyse la façon dont des expériences de testing nationales et internationales enrichissent cette culture globale et, réciproquement, comment celle-ci façonne ensuite les pratiques, représentations et politiques domestiques. Brent Edwards évoque ainsi le cas de la politique EDUCO (Education with Community Participation) qui donne plus de pouvoir aux familles rurales dans le contrôle des résultats de l'enseignement et augmente la reddition de comptes des enseignants envers ces acteurs. Cette politique, initialement développée au Salvador, a été promue 
par la Banque mondiale comme un exemple de bonne pratique à mettre en œuvre dans les pays en développement. Rie Kijima et Jane Leer interrogent les raisons pour lesquelles le Chili a participé très rapidement au mouvement des enquêtes internationales. Au-delà des raisons traditionnellement envi (se comparer à d'autres pays, s'aligner sur les standards internationaux), cette volonté s'explique selon elles par le souhait des autorités nationales de s'appuyer sur ses comparaisons pour renforcer la légitimité et les capacités d'intervention de l'État central. Hilla Aurén et Devin Joshi montrent que le succès de la Finlande repose sur un modèle de testing positif tourné vers une meilleure égalité entre les élèves (supportive testing), plutôt que sur un modèle de contrôle visant à discipliner les acteurs de l'éducation (disciplinary testing). Ce modèle a contribué à façonner une «marque de fabrique » finlandaise dans le monde, même si la reprise à l'étranger de ce modèle n'est pas toujours fidèle. Plusieurs autres analyses sont proposées dans cette partie: une discussion des principales explications des différences de résultats à Pisa obtenus par divers pays (Ji Liu); une analyse critique du programme 2015-2030 de développement durable par l'éducation et la formation continue promu par les Nations Unies (Angeline Barrett) et une étude historique des pratiques d'évaluation au Danemark entre 1945 et les années 1990 (Karen Andreasen et Christian Ydesen).

4 La deuxième partie se concentre sur l'érosion de l'évaluation formative partout dans le monde et le couplage progres du testing avec des sanctions ou des conséquences institutionnelles majeures (high stakes). Sumera Ahsan et William Smith utilisent les travaux de Vygotsky pour montrer que les évaluations en classe des enseignants facilitent beaucoup plus les apprentissages que les évaluations standardisées. Renáta Tichá et Brian Abery formulent plusieurs recommandations visant à ne pas oublier les évaluations formatives. Anthony Somerset analyse les pratiques d'évaluation de plusieurs pays pauvres, en classe et à travers des examens nationaux. Il montre que les attentes et exigences des évaluateurs restent faibles et ne permettent pas d'améliorer les apprentissages. Sean Mulvenon et Sandra Bowman proposent un « récit explicatif » (narrative) permettant de comprendre le développement d'une politique globale du testing. Mariam Orkodashvili, enfin, étudie pour sa part les effets du tutorat privé sur les résultats aux tests internationaux d'élèves pauvres.

5 La troisième partie illustre différentes modalités d'intégration de cette culture globale dans les systèmes éducatifs nationaux. Mobilisant Foucault, Kristine Kousholt et Bjorn Hamre montrent que dans le cas danois, les tests constituent un nouveau dispositif de disciplinarisation des conduites éducatives. Pearl Chung et Hyeonwoo Chea reviennent sur la rupture qu'a connue en 2013 la politique sud coréenne en matière de testing avec l'introduction du programme «Happy Education for Students Dream and Talent ». David Balwanz évoque le cas sud-africain du «National Senior Certificate Exam » et montre, de manière nuancée, la diffusion d'une culture du testing parmi les élèves et les enseignants. Tracy Burns, Patrick Blanchenay et Florian Köster enfin mettent en évidence les grandes difficultés rencontrées par les municipalités suédoises pour développer la reddition de comptes des établissements scolaires et contrôler leurs résultats.

6 S'il contient plusieurs études de cas très intéressantes, cet ouvrage présente deux limites à nos yeux. La question reste posée de l'existence effective de cette culture globale du testing. Dans la mesure où les études de cas illustrent, parfois avec nuance, une diversité de situations - sans oublier d'autres cas allant moins dans le sens de la 
thèse du coordonnateur de l'ouvrage -, la présentation liminaire peine à convaincre, tant elle enferme le testing dans une de ses applications empiriques possibles, celle tournée vers l'évaluation de la performance dans un système décentralisé et dans une perspective néolibérale. On peut dès lors se demander si la perspective de l'ouvrage contribue à réifier cette culture globale plus qu'à n'en démontrer l'existence empirique. Par ailleurs, quand bien même cette culture existerait, on peine à voir la plus-value de cette perspective d'analyse par rapport à d'autres, nombreuses, auxquels les auteurs ne se confrontent pas, pour analyser les processus de mondialisation, de transferts et d'hybridation à l'œuvre.

\section{AUTEUR}

\section{XAVIER PONS}

Xavier Pons est maître de conférences à l'Université Paris-Est Créteil (UPEC), chercheur au Laboratoire interdisciplinaire d'études du politique - Institut Hannah Arendt (EA 7373) et chercheur associé à l'Observatoire sociologique du changement (OSC-Sciences Po). Membre de plusieurs projets de recherche comparatifs depuis 2006, ses travaux de sociologie de l'action publique et des politiques éducatives portent principalement sur les transformations des modes de gouvernance des systèmes éducatifs, les réformes des administrations scolaires, les transformations des États éducateurs en Europe et les modes de structuration du débat public en éducation. Lauréat 2011 du Prix Jean-Claude Eicher pour le développement de la recherche en éducation, il est l'auteur de plusieurs articles et ouvrages sur ces thèmes. Courriel : ponsx@wanadoo.fr 